\title{
Analiza dokładności wyznaczenia położenia nieciągłości punktowych w badaniach ultradźwiękowych z wykorzystaniem głowic podwójnych
}

\author{
The analysis of accuracy of determination \\ of a point-type discontinuity position \\ in ultrasonic testing using a double-transducer probe
}

\section{Streszczenie}

Artykuł dotyczy wykorzystania głowic podwójnych do wykrywania nieciągłości punktowych w ultradźwiękowej metodzie badań nieniszczących. Przedstawiono wyniki badań świadczące o zróżnicowanej charakterystyce wiązki ultradźwiękowej w dwóch wzajemnie prostopadłych kierunkach. Charakterystyka ta wpływa bezpośrednio na wyznaczenie położenia nieciągłości punktowych. Badania wykazały, że wiązka ultradźwiękowa głowicy podwójnej o częstotliwości $4 \mathrm{MHz}$ posiada dwa maksima ciśnienia akustycznego nie pokrywające się z geometrycznym środkiem głowicy. Nieznajomość tejże charakterystyki może skutkować popełnieniem znacznego błędu zarówno w odniesieniu do zlokalizowania nieciągłości, jak i jej oceny na podstawie kryteriów akceptacji zawartych w normach dotyczących badań ultradźwiękowych.

Słowa kluczowe: badania nieniszczące, badania ultradźwiękowe, głowica podwójna

\section{Wstęp}

Głowice podwójne fal podłużnych pozwalają na wykrywanie nieciągłości wewnętrznych w elementach o grubości do około $200 \mathrm{~mm}$. Stosowane są one do kontroli ultradźwiękowej odkuwek i odlewów, wykrywania rozwarstwień i pęknięć lamelarnych w blachach, a także badań złączy spawanych z powierzchni lica spoiny po uprzednim usunięciu nadlewu. Ich zaletą jest bardzo mała - a często praktycznie równa zeru - strefa martwa. Jest to spowodowane znaczną odległością między przetwornikami głowicy a jej powierzchnią roboczą, skutkującą dużym opóźnieniem między momentem detekcji fali z przetwornika nadawczego a momentem wejścia fali do badanego elementu $[1,2]$. Budowę głowicy podwójnej pokazano na rysunku 1.

Echo nieciągłości powstaje na skutek współdziałania nadajnika i odbiornika wtedy, gdy nieciągłość jest w zasięgu wiązki fal wysłanych z nadajnika, a wiązka fal odbitych trafia do odbiornika (rys. 1). Rozkład czułości głowicy podwójnej jest specyficzny i zależy od kilku czynników:

- kształtu i wielkości przetworników,

- odległości między przetwornikami,

- kąta nachylenia przetworników względem geometrycznej

\section{Abstract}

The article concerns the use of double-transducer probes for detecting point-type discontinuities in the ultrasonic non-destructive test method. The results of studies demonstrate the different characteristic of the ultrasonic beam in two mutually perpendicular directions. The characteristic directly affects the determination of a position of a point-type discontinuity. Studies have shown that the ultrasonic beam formed by double probe with $4 \mathrm{MHz}$ frequency has two sound pressure maxima that do not coincide with the geometrical centre of the probe. Unfamiliarity with the characteristic may result with committing a significant error both in relation with location of discontinuity, as well as its assessment on the basis of the acceptance criteria contained in the standards for ultrasonic testing.

Keywords: non destructive testing, ultrasonic testing, double transducer probe

\footnotetext{
Mgr inż. Rafał Kaczmarek - Politechnika Częstochowska, Zakład Spawalnictwa.
} 
inna jest szerokość jej wiązki mierzona w kierunku prostopadłym do płaszczyzny rozdziału (tzn. izolacji akustycznej), niż w kierunku równoległym do płaszczyzny rozdziału. Ponieważ przetworniki są zazwyczaj prostokątne, to pierwsza z przytoczonych wartości jest mniejsza, a druga większa. Jak wykazały przedstawione poniżej wyniki badań, fakt ten ma duże znaczenie w kontekście dokładności wyznaczenia położenia nieciągłości punktowych. W pewnych przypadkach może mieć to znaczący wpływ na końcową ocenę kontroli jakości całego elementu badanego $[3,4]$.

\section{Metodyka i wyniki badań}

Badanie przeprowadzono przy pomocy defektoskopu USM 36 i głowicy podwójnej DL4R-6x20 nr 867964 o częstotliwości $4 \mathrm{MHz}$ i wymiarach przetworników $6 \times 20 \mathrm{~mm}$. Nieciągłość punktowa nr $1 \mathrm{w}$ badanej próbce została wykonana poprzez nawiercenie otworu płaskodennego o średnicy $2 \mathrm{~mm}$. Znajdowała się ona na głębokości $29 \mathrm{~mm}$ w stosunku do powierzchni badania. Szkic fragmentu próbki wraz z przyjętym sposobem pomiaru odległości x(1) przy wyznaczaniu obwiedni echa przedstawiono na rysunku 2.

\section{Kierunek przesuwu głowicy w pozycji $A$}

a)

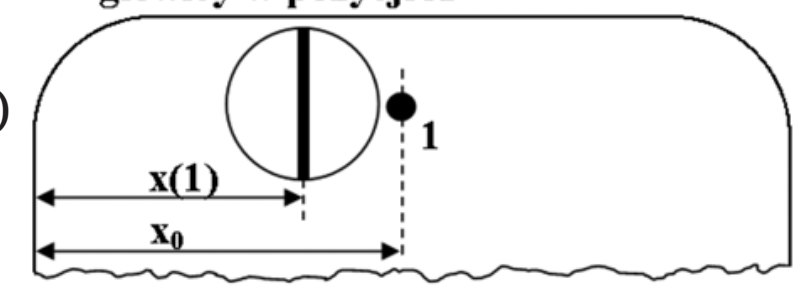

Kierunek przesuwu głowicy $w$ pozycji $B$

b)

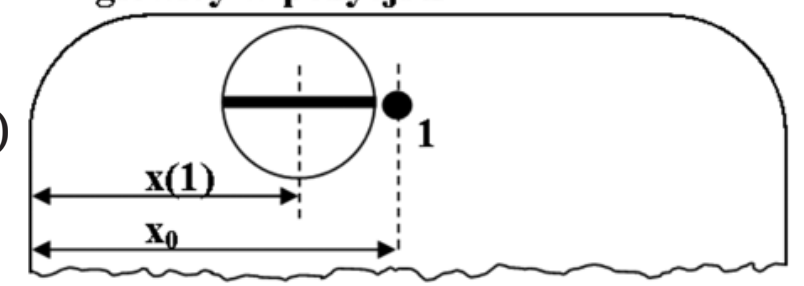

Rys. 2. Schemat oznaczenia wartości $x(1)$ przy rejestracji obwiedni echa od nieciągłości nr 1: a) płaszczyzna rozdziału głowicy podwójnej zorientowana poprzecznie do kierunku przesuwu głowicy, b) płaszczyzna rozdziału głowicy podwójnej zorientowana wzdłuż kierunku przesuwu głowicy

Fig. 2. Scheme of value $x(1)$ designation for the boundary of registration echoes from discontinuity $1:$ a) acoustical barrier oriented perpendicularly to the direction of probe movement $b$ ) acoustical barrier oriented parallel to the direction of probe movement

Przeprowadzone badanie polegało na rejestracji przekroczenia decybelowego $\Delta \mathrm{V}$ względem krzywej DGS (odległość - wzmocnienie - rozmiar) dla reflektora płaskodennego o średnicy $D_{D S R}=1,5 \mathrm{~mm}$. Jego istotą było zarejestrowanie obwiedni echa przy przesuwie głowicy nad nieciągłością punktową w kierunku krawędzi próbki, przy dwóch wzajemnie prostopadłych orientacjach głowicy podwójnej - płaszczyzna rozdziału głowic była zorientowana poprzecznie (pozycja A) oraz wzdłużnie (pozycja B) do kierunku przesuwu głowicy (rys. 2). Rejestracji wartości $x(1)$, będącej odległością między geometrycznym środkiem głowicy a krawędzią próbki, dokonano z dokładnością wynoszącą $0,5 \mathrm{~mm}$. W ten sposób otrzymano dwie obwiednie echa od nieciągłości punktowej nr 1, uzyskane przy zastosowaniu tej samej głowicy podwójnej, jednakże różnie zorientowanej w stosunku do kierunku przesuwu głowicy.

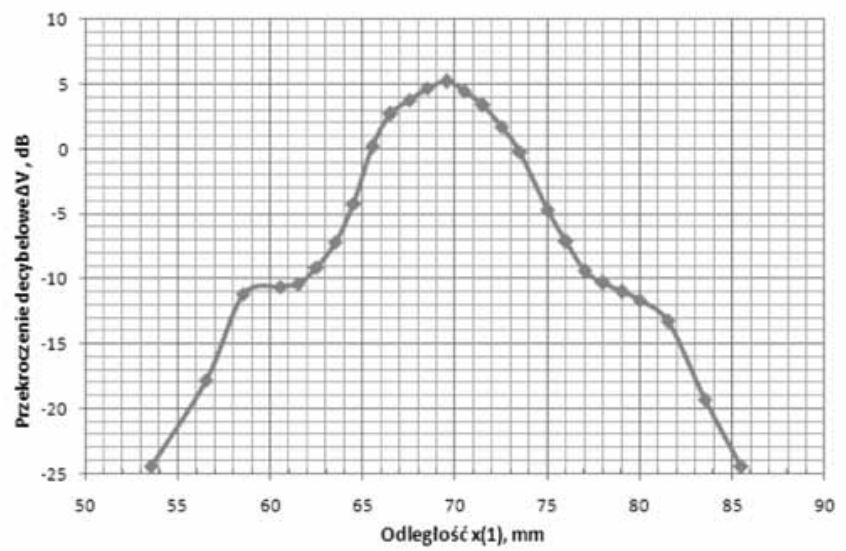

Rys. 3. Obwiednia echa od nieciągłości punktowej nr 1 przy orientacji głowicy w pozycji A - płaszczyzna rozdziału głowicy podwójnej zorientowana poprzecznie do kierunku przesuwu głowicy

Fig. 3. Boundary of echoes from the discontinuity point No. 1 when the probe oriented in position A - acoustical barrier oriented transversely to the direction of travel of the head oriented perpendicularly to the direction of probe movement

$\mathrm{Na}$ wykresie (rys. 3) zamieszczono obwiednię echa uzyskaną przy przesuwie głowicy w pozycji A, tzn. z powierzchnią rozdziału skierowaną poprzecznie. Wykazuje ona maksimum amplitudy $(\triangle \mathrm{V}=5 \mathrm{~dB})$ dla wartości $x(1)=69,5 \mathrm{~mm}$, podczas gdy rzeczywista odległość nieciągłości punktowej od krawędzi próbki wynosi $\mathrm{x}_{0}=70 \mathrm{~mm}$. Zatem takowa pozycja głowicy przy określaniu położenia nieciągłości punktowej skutkuje bardzo precyzyjnym wyznaczeniem jej lokalizacji, nieznacznie różniącym się od rzeczywistego. Popełniony błąd w ocenie położenia środka nieciągłości wynosi 0,5 mm. Echo od nieciągłości stopniowo wzrasta, uzyskując maksimum wówczas, gdy płaszczyzna rozdziału znajduje się nad środkiem nieciągłości punktowej, po czym stopniowo maleje.

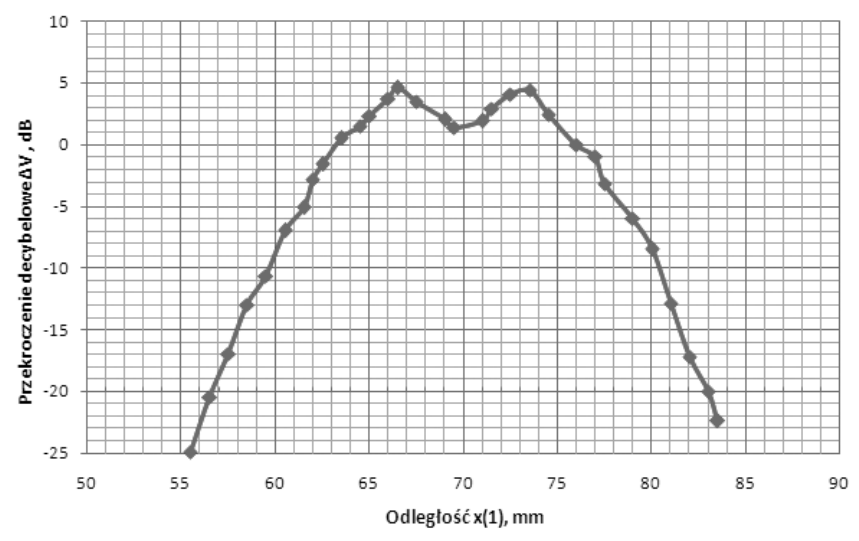

Rys. 4. Obwiednia echa od nieciągłości punktowej nr 1 przy orientacji głowicy w pozycji B - płaszczyzna rozdziału głowicy podwójnej zorientowana wzdłuż kierunku przesuwu głowicy

Fig. 4. Boundary of echoes from the discontinuity point No. 1 when the probe oriented in position B - acoustical barrier oriented transversely to the direction of travel of the probe oriented along the direction of probe movement

Na rysunku 4 zamieszczono wykres obwiedni uzyskanej przy przesuwie głowicy w pozycji B, tzn. z płaszczyzną rozdziału skierowaną wzdłuż kierunku przesuwu głowicy. Jak widzimy, obwiednia uzyskana w ten sposób znacząco różni się od opisanej powyżej. Wykazuje ona dwa maksima przesunięte od geometrycznego środka głowicy o około 3,5 mm. Pierwszy szczyt obwiedni występuje przy wartości $x(1)=66,5 \mathrm{~mm}$, natomiast drugi przy wartości $x(1)=73,5 \mathrm{~mm}$, przy czym obydwa wykazują taką samą amplitudę wynoszącą $\Delta \mathrm{V}=5 \mathrm{~dB}$. Pomiędzy nimi występuje lokalne minimum pokrywające się z geometrycznym środkiem głowicy podwójnej. Spadek amplitudy echa między lokalnym minimum i maksimum obwiedni wynosi w przybliżeniu 3dB. 
Na wykresie (rys. 5) zestawiono obwiednie uzyskane dla pozycji A i B w funkcji odległości od geometrycznego środka głowicy. Znając rzeczywistą odległość $x_{0}=70 \mathrm{~mm}$ środka badanej nieciągłości punktowej od krawędzi próbki, będącej bazą pomiarową przy określaniu wartości x(1), wyznaczono odległość nieciągłości od geometrycznego środka głowicy $X=x(1)-x_{0}$. W ten sposób uzyskano charakterystykę spadku amplitudy echa dla dwóch wzajemnie prostopadłych osi symetrii głowicy podwójnej. Jak widzimy, wiązka głowicy podwójnej o częstotliwości $4 \mathrm{MHz}$ i wymiarach przetworników $6 \times 20 \mathrm{~mm}$ posiada dwa maksima ciśnienia akustycznego, nie pokrywające się z jej środkiem geometrycznym. Maksima te leżą wzdłuż osi rozdziału głowicy i są oddalone od siebie o ok. $7 \mathrm{~mm}$. Oznacza to, że wyznaczanie położenia nieciągłości punktowej poprzez poszukiwanie najwyższego echa przy niekorzystnej orientacji głowicy (pozycja B), każdorazowo skutkuje popełnieniem błędu. Wyznaczona wówczas lokalizacja nieciągłości jest przesunięta o 3,5 mm wzdłuż płaszczyzny rozdziału głowic od rzeczywistego położenia nieciągłości. Błąd ten może zostać zwielokrotniony w przypadku wyznaczania odległości między nieciągłościami. Sytuację tą pokazano na rysunku 6, przyjąwszy odległość między nieciągłościami punktowymi(zielone punkty) równą $40 \mathrm{~mm}$. Jeżeli pomiar odległości między nimi nastąpiłby przy niekorzystnej orien-

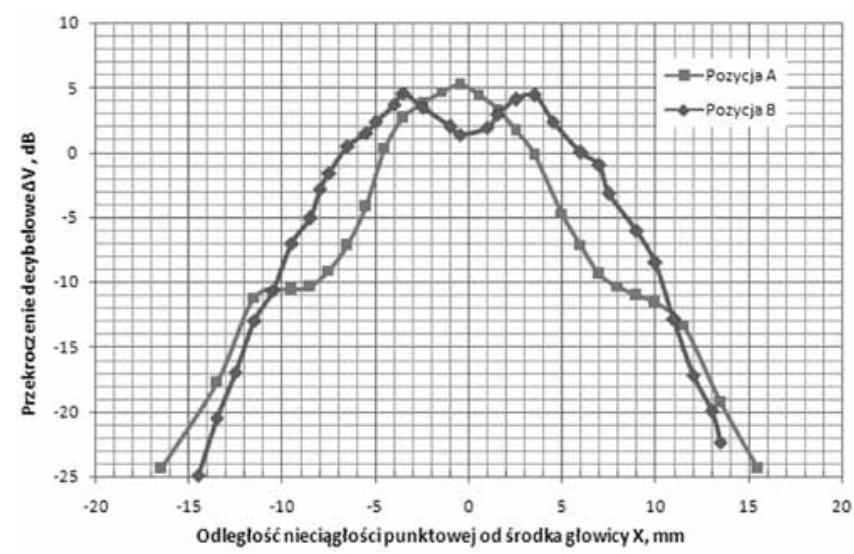

Rys. 5. Obwiednia echa nieciągłości punktowej nr 1 przy orientacji głowicy w pozycjach A i B w funkcji odległości nieciągłości od geometrycznego środka głowicy

Fig. 5. Boundary of echoes from the discontinuity point No. 1 on the orientation of the probe at positions $A$ and $B$ as a function of the distance of discontinuity from the geometric centre of the probe tacji głowicy (pozycja B), wtedy w dwóch skrajnych przypadkach wyznaczona odległość będzie wynosiła $33 \mathrm{~mm}$ oraz $47 \mathrm{~mm}$, co daje $14 \mathrm{~mm}$ różnicy między możliwymi pomiarami (rys. 6a). W wielu przypadkach takowa różnica odległości powoduje zmianę kryteriów oceny wskazań. Przykładem może być ocena wad punktowych w odkuwkach na podstawie PN-EN 10228-3 [5]. Według przywołanej normy wady punktowe, między którymi odległość jest mniejsza bądź równa $40 \mathrm{~mm}$, są zaliczane do wad punktowych skupionych - i tym samym - podlegają bardziej rygorystycznym kryteriom oceny. Natomiast nieciągłości oddalone o więcej niż $40 \mathrm{~mm}$ stanowią wady punktowe odosobnione i są oceniane według łagodniejszych kryteriów. W ten sposób dwa badania wykonane przez jednego operatora, przy pomocy tego samego wyposażenia badawczego, mogą dać odmienny wynik - i co się z tym wiąże - inną klasę jakości odkuwki. Zobrazowany na rys. 6 a przykład pokazuje, że nawet niewielkie 3,5 milimetrowe przesunięcie maksimum obwiedni od środka głowicy może w pewnych przypadkach przyczynić się do błędnego wyniku badania. $Z$ tego względu wyznaczenie położenia nieciągłości, a zwłaszcza odległości między nimi, powinno być realizowane przy orientacji głowicy w pozycji $A$ (rys. 6b). W ten sposób wynik badania będzie powtarzalny i bliski rzeczywistej odległości między lokalizowanymi nieciągłościami. a)

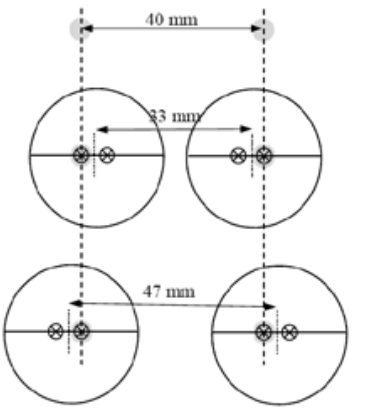

b)

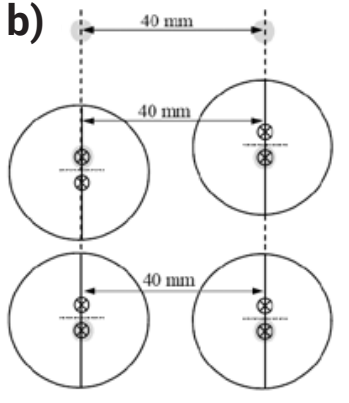

Rys. 6. Wyznaczanie odległości między nieciągłościami punktowymi: a) niepoprawne, prowadzące do znacznego błędu (orientacja głowicy w pozycji B); b) poprawne, eliminujące możliwość zaistnienia znacznego błędu (orientacja głowicy w pozycji A)

Fig. 6 . The determination of a distance between point-type discontinuities: a) incorrect, may lead to the considerable mistake (the orientation of the probe at positions B); b) correct, the possibility of considerable mistake is eliminated (the orientation of the probe at positions $\mathrm{A}$ )

\section{Wnioski}

Opisane w artykule badania wykazały, że wiązka ultradźwiękowa głowic podwójnych o częstotliwości $4 \mathrm{MHz}$ i wymiarach przetworników $6 \times 20 \mathrm{~mm}$ wykazuje dwa maksima ciśnienia akustycznego. Są one zlokalizowane wzdłuż płaszczyzny rozdziału głowic (izolacji akustycznej) i oddalone od geometrycznego środka głowicy o ok. 3,5 mm w kierunku zewnętrznej krawędzi głowicy. Fakt ten utrudnia precyzyjne wyznaczenie położenia nieciągłości punktowych i w niektórych przypadkach może być przyczyną znacznych różnic w ocenie wykrytych wskazań, a nawet całych elementów badanych. Sytuacja ta dotyczy zwłaszcza wyznaczenia odległości między dwoma sąsiadującymi nieciągłościami, przy której może dojść do zwielokrotnienia popełnionego błędu. Zaproponowano sposób badania eliminujący możliwość błędnej lokalizacji wykrytych nieciągłości związany z odpowiednią orientacją głowicy w stosunku do kierunku jej przesuwu przy wyznaczaniu położenia nieciągłości. Warto nadmienić, że poprawność opisanych wyników badań zweryfikowano przy użyciu kilkunastu głowic podwójnych danego typu (4 MHz, 6x20 mm, dwóch producentów) stosując nieciągłości na różnych głębokościach. Każdorazowo uzyskane wyniki były zbliżone do zaprezentowanych w niniejszym artykule, potwierdzając tym samym zasadność wyciągniętych wniosków.

\section{Literatura}

[1] J. Deputat: Badania ultradźwiękowe Podstawy. Instytut Metalurgii Żelaza im. Stanisława Staszica, Gliwice, 1979.

[2] A. Szymański: Kontrola i zapewnienie jakości w spawalnictwie Tom 2 Wydawnictwo Politechniki Śląskiej, Gliwice, 1998.

[3] R. Kaczmarek, R. Krawczyk: Projektowanie i wytwarzanie konstrukcji spawanych $\mathrm{w}$ aspekcie możliwości przeprowadzenia badań ultradźwiękowych wykonanych złączy. Przegląd Spawalnictwa, 2014, nr 7.
[4] J. Słania: „Plany spawania Teoria i praktyka”, Wydawnictwo SIMP, Warszawa, 2013.

[5] PN-EN 10228-3 Badania nieniszczące odkuwek stalowych Badanie ultradźwiękowe odkuwek ze stali ferrytycznych i martenzytycznych. 